\title{
Amplitude Versus Offset Modeling of the Bottom Simulating Reflection Associated with Submarine Gas Hydrates
}

\author{
Uma Shankar, Babita Sinha, N. Satyavani, B. Ashalata, S.I. Reddi \& N.K. Thakur \\ National Geophysical Research Institute, Hyderabad
}

\begin{abstract}
Velocity analysis of Multi-channel Seismic (MCS) data and Amplitude Versus Offset (AVO) modeling will provide an efficient way of identifying gas hydrate and free gas, and therefore the nature of the BSR. Additionally, AVO modeling will also yield controls on estimates of the hydrate concentration and free gas saturation across the BSR. In the present study we apply directivity correction for obtaining true amplitude versus offset and modeling for velocity ratio across BSRs for MCS data over Kerala-Konkan offshore basin, which leads to the probable estimates of Gas Hydrates and underlying free-gas. Initial results indicate the possible presence of free gas underlying the Gas Hydrate saturated sediments in this region.
\end{abstract}

KEYWORDS: Gas hydrate; BSR; Seismic data; seismic processing; modeling; AVO-studies

\section{INTRODUCTION}

Gas Hydrates are being increasingly recognized as a potential future energy resource. Assessments have shown that worldwide there might be twice as much energy available from hydrate reservoirs than from all other conventional forms of energy. Most of the information on gas hydrates has come from a wide range of seismic surveys, including the mapping of the area with the characteristic bottom-simulating reflector (BSR) (Andreassen et al, 1995; MacKay et al, 1994; Miller et al, 1991; Rowe and Gettrust, 1993). BSRs that parallel the sea floor occur at several places on the seismic profiles in the outer continental margins worldwide. The BSR coincides with the base of the gas hydrate stability field and is commonly used as an indicator of natural submarine gas hydrates. Despite the widespread assumption that the BSR marking the base of the gas hydrates bearing sediments, the occurrence and the importance of free gas in the sediments beneath the BSR has long been a subject of debate. Determining the depth and distribution of hydrate, underlying free gas, and the geological controls of hydrate formation have been attempted in many locales over the globe through special seismic studies. Such studies include BSR reflection coefficients, the frequency dependence of the BSR amplitude, BSR amplitude- versusoffset (AVO), and full waveform inversion.

\section{METHODOLOGY}

In most cases of hydrocarbon exploration studies, the extracted seismic amplitude information is used in determining the reservoir characteristics and possible causes of reflections. The analyses of AVO (Lee et al, 1993; Andreassen et al, 1997) and waveform inversion (Singh et al, 1993; Minshull et al, 1999) are the two major techniques used in characterizing the petro-physical properties of the formations and in quantifying the resources. Presence of water/gas at an interface is known to produce characteristic variations in the reflection amplitude as a function of offset. Therefore AVO analysis along with velocity structure provides important information on the associated hydrate deposits.

For AVO analysis, the raw dataset is to be corrected for all possible energy losses to obtain relative true amplitudes. In normal processing true amplitude recovery is based on applying correction for spherical divergence and attenuation. This is not adequate for the AVO analysis. To condition the data set for AVO analysis, in addition to usual corrections, it is necessary to apply Directivity corrections (offset amplitude recovery) (Hyndmann \& Spence, 1992). These corrections are applied using time and offset variant gain functions to seismic traces to compensate for loss of amplitude due to source and receiver array attenuation and emergence angle. These corrected reflection amplitudes together with interval velocities can then be used for the estimation of bulk volume of hydrate and free gas in marine sediments.

\section{EXAMPLE}

The present study is aimed at demonstrating the importance of the directivity correction. MCS data collected in the Kerala-Konkan offshore of Western Indian Continental Margin shows some BSR like reflectors (Reddi et al, 1998; Rao et al, 2001). A strong reflector with reverse polarity is observed at $400 \mathrm{~ms}$ Two Way Travel Time (TWT) below sea floor at a water depth of $2500 \mathrm{~ms}$ TWT (Fig.1). The application of the directivity correction to the data has resulted in the enhancement of amplitudes with offset (Fig. 2). The characteristic increase in the amplitude with offset suggests the possible association of gas-saturated sediment underlying the hydrate layer. Theoretical curves of reflection amplitude versus emergence angle have been generated using Zeoppritz equations (Aki \& Richards, 1980) for various V1,V2 ratios. On 


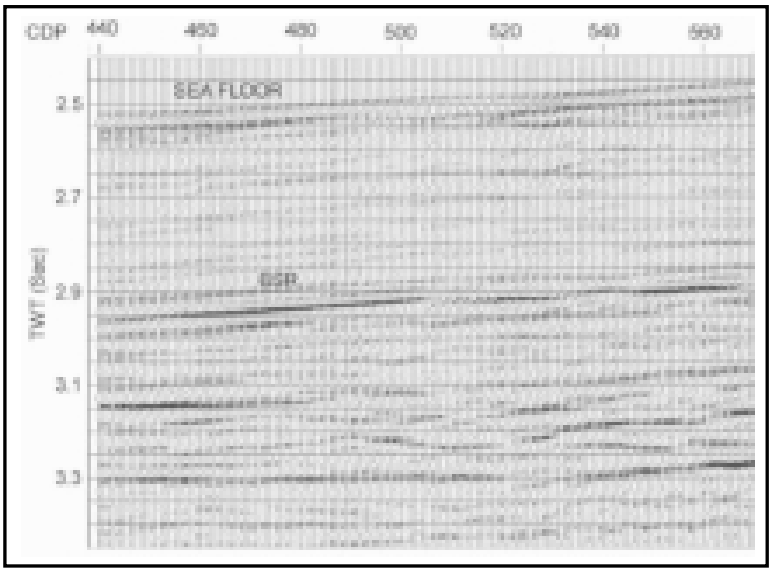

Figure $1:$ Stack Section

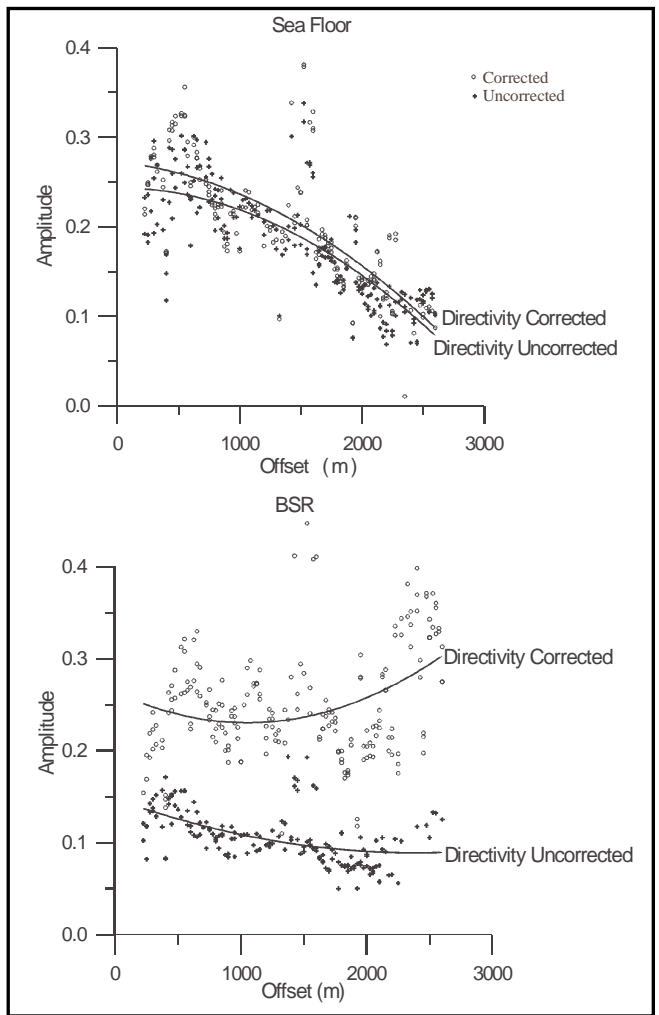

Figure: 2: AVO for CDP Gather for Sea floor and BSR

comparison of the observed corrected reflection amplitudes with the theoretical curves we obtained the velocities across the BSR. These results provide important constraints in modeling the distribution of Gas Hydrate / Free gas and formation of the BSRs in this region.

\section{CONCLUSION}

Segments of stacked MCS sections in the KeralaKonkan basin is characterized by BSRs like features. AVO analysis and modeling carried out for relative-true-amplitude recovered data, which is also subjected to Directivity correction, provides additional controls on the identification and quantification of hydrate deposit and underlying gassaturated sediments.

\section{ACKNOWLEDGEMENTS}

The authors wish to thank Dr. V.P.Dimri, Director, NGRI and Gas Authority of India Ltd. for their kind consent to publish this work.

\section{REFERENCES}

Andreassen, K., Hart, P.E., Grantz, A., 1995, Seismic Studies of a bottom simulating reflection related to gas hydrate beneath the continental margin of the Beaufort Sea, J.Geophys. Res., 100, 12659-12673.

Andreassen, K., Hart, P.E., MacKay.M. 1997, Amplitude versus offset modeling of the bottom simulating reflection associated with submarine gas hydrates. Marine Geology, 137, 25-40.

Hyndmann, R.D., and Spence, G.D., 1992, A Seismic Study of Methane Hydrate Marine Bottom Simulating Reflectors. J.Geophys.Res., 97, 6683-6698.

Lee, M.W., Hutchtinson, D.R., Dillon, W.P., Miller, J.J., Agena, W.F., Swift, B.A., 1993, Use of Seismic Data in estimating the amount of In-Situ gas hydrates in deep marine sediment. In Future of Energy gases, USGS Professional Paper 1570.

MacKay, M.E., Jarrad, R.D., Westbrook, G.K., Hyndmann, R.D., and the Shipboard Scientific Party of ODP leg 146, 1994, Origin of bottom simulating reflectors: Geophysical Evidence from the Cascadia Accretionary prism, Geology, $22,459-462$.

Miller, J.J., Lee, M.W., and Huene, R., 1991, An analysis of a seismic reflection from the base of a Gas Hydrate Zone, Offshore Peru, Amer.Assoc.Petrol.Geol. Bull., 75, 910924.

Minshull, T.A., Singh, S.C., Westbrook, G.K., 1994, Seismic structure at a gas hydrate reflector, offshore western Colombia, from full waveform inversion, J., Geophys.Res., 99, 4715-4734.

Rao, Y.H., Subramanyam, C., Rastogi, A., Deka, B., 2001, Anamalous features related to Gas / Gas hydrate occurrences along the western continental margins of India, Geo-Marine Lett. $21,1-8$.

Reddi S.I., Thakur, N.K., Ashalatha, B., Kalachand Sain, 2001, Reprocessing of Multi-channel seismic data of ONGCL for gas hydrate exploration in offshore Goa, National Geophysical Research Institute (NGRI) Tech Rep. No. 2001-EXP-307.

Rowe, M.M., and Gettrust, J.F., 1993, Fine Structure of Methane Hydrate Bearing sediments on the Blake Outer Ridge as Determined from Deep-Tow Multichannel Seismic data, J.Geophys.Res., 98, 463-473.

Singh, S.C., Minshull, T.A., Spence, G.D., 1993 Velocity structure of a gas hydrate reflector, Science, 260, 204-207. 